$\underline{\text { Research Articles }}$

\title{
Eastern European Roma: ethnic discrimination in the public healthcare system
}

\author{
Brandon Muncan* \\ Keywords: global health \\ https://doi.org/10.29392/joghr.2.e2018025
}

\section{Journal of Global Health Reports}

Vol. 2, 2018

\begin{abstract}
The term "human rights" describes the inherent, equal, and irrevocable freedoms of the individual, and includes access to the basic necessities of life, freedom of expression, right to justice, and state of peace. Among these rights is access to quality healthcare and medical treatment for chronic and acute illness. In Eastern Europe, the Roma minority experience limitations to the provision of quality medical care as a result of cultural, ethnic, and racial stigma. Such discrimination results from historic sociocultural and economic seclusion across the entire European Romani diaspora, and leads to higher disease incidence and mortality amongst members of this ethnic group. This paper examines some of the barriers Roma face in Eastern European healthcare systems and provides considerations for future social changes to allow all citizens and patients access to equal treatment.
\end{abstract}

\section{DEFINING DISCRIMINATION IN HEALTHCARE}

Despite the fact that in developed nations, availability of care to underrepresented populations and minorities is an active priority both within political systems and healthcare networks, in developing nations, discrimination in healthcare is an ongoing and often overlooked issue.

Discrimination constitutes "any distinction, exclusion, restriction or preference or other differential treatment that is directly or indirectly based on the prohibited grounds of [prejudice] and which has the intention or effect of nullifying or impairing the recognition, enjoyment or exercise, on an equal footing, of Covenant rights," and may be directed against an individual or group of individuals by a person, network, organization, or establishment, on the basis of (but not limited to) age, sex, gender, gender orientation, race, ethnicity, national origin, creed, language, socioeconomic and political standing, physical and/or mental illness, and religion. ${ }^{1}$

Discrimination of any sort in the healthcare system plays a role in increasing morbidity and mortality through the enactment of unequal treatments that impact the nature of care. ${ }^{2}$ Ethnic minority patients, and in particular, Roma in the European healthcare systems face such discriminatory challenges, thereby limiting the quality of care received and increasing the risk of disease progression, co-morbidities, and death.

\section{THE ROMA}

Although this paper discusses the discrimination faced by Roma in several European medical systems, it is imperative to understand the sociocultural status of the Roma both in a historic and contemporary European sense. Genomic evidence seems to identify the Romani as an independent North-Indian population that began westward migration circa the $11^{\text {th }}$ century C.E. ${ }^{3}$ While different hypotheses ex- ist, more and more evidence suggests the cause of the Romani migration lies within Persian mercenary and MiddleEastern slavery activity. From this initial migration, Romani groups split geographically, and created a European diaspora by the $16^{\text {th }}$ century. ${ }^{1}$ Most native Europeans did not accept Romani culture, family structure, or belief systems, as many opined the Roma were abject, deceitful and exploitative. ${ }^{4}$ Consequently, the Romani diaspora in all of Europe suffered ethnic discrimination across the entire timespan of the modern era. Ostracization of the "gypsies" and "travelers" became commonplace, especially in Eastern Europe, and the Romani culture became socially synonymous with thievery and apathy. Such an "identity sequestration" lead the Roma people to group together in ethnic enclaves, and to rely upon one another, rather than on national and local governments for support. Over time, increasing social and cultural distance from native Europeans led to an exacerbated dislike and continued discrimination against the Roma.

The twentieth century saw some of the most violent acts of hatred toward the Roma throughout Europe. In Nazi Germany, "Gypsies" were considered defamers of Aryan blood, and were removed from their homes and placed in concentration camps; many fell victim to mass murder. In all, death tolls are approximated at 80,000 to 1,000,000 Roma. 4 Additional racist policies were implemented in the communist Eastern bloc, particularly in Romania. Despite relative acceptance at the beginning of the Ceausescu regime, Roma were no longer considered a minority group and were removed from the national "co-inhabiting nationalities list" by the 1970s. ${ }^{5}$ After the fall of communism, however, the plight of the Roma only worsened. Mass social marginalization and discrimination in public systems such as health, emergency services, and education led to ever-increasing wealth, status, and rights-gaps, gaps which persist to this day, particularly in Eastern Europe. 


\section{ACCESSING HEALTHCARE}

When examining the obstacles Roma face in the healthcare system, it is imperative to consider medical/health education and availability of care from a holistic perspective. Due to societal discrimination, Roma children and adults alike are less likely to be well-informed about the need to seek medical attention and advice regularly. ${ }^{1}$ In secluded Romani communities, it is often the case that general family care is limited or even absent, and health education in schools lacks the structure to demonstrate to students the necessity of physical, sexual, and psychological well-being. Roma therefore often neglect their medical needs, thereby leading to a higher incidence of morbidity and mortality from infections and chronic illnesses. ${ }^{6}$ One multinational study has found that pregnant Romani women were unaware of their rights to care, and therefore had a higher rate of peripartum complications compared to non-Roma counterparts. ${ }^{7}$ Similarly, the rates of teenage pregnancy, sexually-transmitted infections, and elective termination of pregnancy are much higher in Roma populations as a result of limited sexual education. 8

Another major barrier to accessing care is availability of culturally-competent medical practitioners and responsiveness of medical service networks. Parvu reports an interview with a Romani woman of the Kaldarash community (Iasi, Romania) in which she describes emergency medical service refusal to enter the Roma community in order to transport a patient. ${ }^{9}$ Indeed, it is commonplace for ambulance services not to treat and transport patients in separate Roma settlements due to discriminatory stereotypes of uncleanliness and a dangerous atmosphere. Such attitudes lead to an increased incidence of acute disease and complications, particularly in maternity and pediatric wards. 1

\section{PHYSICIAN ATTITUDES AND QUALITY OF CARE}

A key issue in discriminatory attitudes towards Roma is the attitude of the healthcare provider toward the patient. Several authors discuss commentaries from Roma in hospitals and other healthcare settings in which attitudes of racism by doctors and nurses have prevented quality care delivery and have negatively impacted patient prognosis. 1,9 Many Roma feel as if cultural stereotypes of thievery, lying, manipulation, and uncleanliness leads to the separation of patients based on ethnicity and the preferential treatment of caucasians over members of their own community. Parvu, 2013 reports that most Roma interviewees believed ethnic discrimination and subsequent sub-standard care was expected from non-Roma physicians. ${ }^{9} \mathrm{Nev}-$ ertheless, the medical and psychological consequences of discrimination is evident and has reached a critical level. Within the Romanian public healthcare system for example, many Roma report being neglected by doctors and nurses, which leads to acute exacerbation of underlying conditions. Particularly, with chronic diseases such as hypertension, diabetes mellitus, and end stage renal disease, access to care for Romanian Roma is limited, and quality of care is diminished because many physicians think of Roma as "lower class citizens." Galdean, 2011 concludes that being of Romani ethnicity is an independent risk factor for end-stage renal disease, with an $8.5 \%$ higher 3 -year mortality rate in Roma compared to Caucasians. ${ }^{6}$ Additionally, in many maternity wards across Europe, the rates of obstetric and gynecologic complications of pregnancy i.e. Hemorrhage, infection, exogenous failure to thrive of neonates, and psychological consequences such as postpartum depression and postpartum psychosis are are much higher in Romani women as opposed to other ethnicities. ${ }^{1}$

\section{CONSIDERATIONS FOR THE FUTURE}

As Eastern Europe sees an increase not only in Roma population, but in population of minorities in general, legislative, and social changes must be enacted to ensure that the basic human right of quality healthcare is met for all citizens regardless of race, ethnicity, national origin, creed, etc. It is imperative that governing bodies, health and human rights organizations, hospitals, EMS directorships and schools discuss the meaning of respect, equality, and equal treatment in order to lower the Roma morbidity and mortality, and promote cultural, social, and economic inclusion of the Roma in day-to-day affairs.

\section{ACKNOWLEDGEMENTS}

Special thanks to Catherine Marrone for her continual help, critique, and encouragement.

Funding: No funding was received for this project.

Competing interests: The author has completed the Unified Competing Interest form at http://www.icmje.org/ coi_disclosure.pdf (available on request from the corresponding author) and declares no conflict of interest.

Correspondence to:

Brandon Muncan

Stony Brook University

100 Nicolls Rd

Stony Brook, N.Y. 11794

United States of America

brandon.muncan@stonybrook.edu 


\section{REFERENCES}

1. Watson HL, Downe S. Discrimination against childbearing Romani women in maternity care in Europe: A mixed-methods systematic review. Reprod Health. 2017;14(1). doi:10.1186/s12978-016-0263-4

2. Gruskin S, Daniels N. Process is the point: Justice and human rights: Priority setting and fair deliberative process. Am J Public Health. 2008;98(9):1573-1577. doi:10.2105/ajph.2007.123182

3. Mendizabal I, Lao O, Marigorta UM, et al. Reconstructing the population history of European Romani from genome-wide data. Current Biology. 2012;22(24):2342-2349. doi:10.1016/j.cub.2012.10.03 $\underline{9}$

4. Loveland MT, Popescu D. The Gypsy threat narrative: Explaining anti-Roma attitudes in the European Union. Humanity \& Society. 2016;40(3):329-352. doi:10.1177/0160597615601715

5. Achim V. The Roma in Romanian History. Budapest: Central European University Press; 1998.
6. Gadalean F, Lighezan D, Stoian D, et al. The Survival of Roma Minority Patients on Chronic Hemodialysis Therapy - A Romanian Multicenter Survey. Jha V, ed. PLOS ONE. 2016;11(5):e0155271. do i:10.1371/journal.pone.0155271

7. Janevic T, Sripad P, Bradley E, Dimitrievska V. "There's no kind of respect here" A qualitative study of racism and access to maternal health care among Romani women in the Balkans. International Journal for Equity in Health. 2011;10(1):53. doi:10.1186/147 5-9276-10-53

8. Škarić-Jurić T, Klarić IM, Narančić NS, Drmić S, Salihović MP, Lauc LB. Trapped between tradition and transition-anthropological and epidemiological cross-sectional study of Bayash Roma in Croatia. Croat Med J. 2007;48(708).

9. GRAMMA R, ENACHE A, et al. Stigma and Discrimination against Rroma Patients in the Romanian Healthcare System. po. 2013;4(4):51-65. do i:10.18662/po/2013.0404.06 